\title{
Influence of experimental staining on the color stability of indirect computer-aided design/ computer-aided manufacturing dental provisional materials
}

\author{
Thamer Almohareb ${ }^{1}$, Mohammed S. Alkatheeri ${ }^{1}$, Fahim Vohra ${ }^{2}$, Ali Alrahlah ${ }^{1}$
}

Correspondence: Dr. Ali Alrahlah

Email: aalrahlah@ksu.edu.sa

\begin{abstract}
'Departments of Restorative Dental Sciences, College of Dentistry, King Saud University, Riyadh,

Saudi Arabia,

2Department of Prosthetic Dental Science, College of Dentistry, King Saud University, Riyadh, Saudi Arabia
\end{abstract}

\section{ABSTRACT}

Objective: This study presents a comparative analysis of the color stability of computer-aided design/computer-aided manufacturing (CAD/CAM)-fabricated provisional restorations with those of conventional restorations. Materials and Methods: Three different provisional restorative materials (Systemp C\&B, 3M Protemp 4, and Telio CAD) were inspected for their color stability using four solutions (Pepsi, coffee, tea, and distilled water). All samples used were fabricated using A1 shade by following the manufacturer's instructions. Color assessment was performed using CIELAB system and a colorimeter. After baseline color measurement, color assessments were done weekly after immersion in specified solutions. Triplicate readings were taken for every sample and the mean value of the color coordinates $\left(L^{*}\right),\left(a^{*}\right)$, and $\left(b^{*}\right)$ were recorded at baseline, week 1 , week 2 , week 3 , and week 4 . The data within different groups were compared statistically using analysis of variance $(\alpha=0.05)$. Results: Overall, the highest color stability was found in CAD/CAM material, followed by Protemp and SystempC\&B. It was also observed that the maximum color variation was observed in case of coffee, followed by tea and Pepsi. Conclusions: CAD/ CAM provisional material (Telio CAD) showed better color stability compared to conventional materials (Protemp 3M ESPE and SystempC\&B Ivoclar Vivadent). CAD/CAM provisional materials are recommended for long-term temporization procedures. This is attributed to the prepolymerization, higher monomer conversion, and minimal preparation errors in CAD/CAM materials.

Key words: Bis-Acryl, computer-aided design/computer-aided manufacturing, color stability, polymethyl methacrylate, provisional restoration

\section{INTRODUCTION}

In contemporary dental practice, provisional indirect restorations represent an important treatment step and serve as protective shields for teeth against thermal, mechanical, and physical stresses. With the advances in technologies and the ease of implementing computers into dentistry, novel methods of provisional

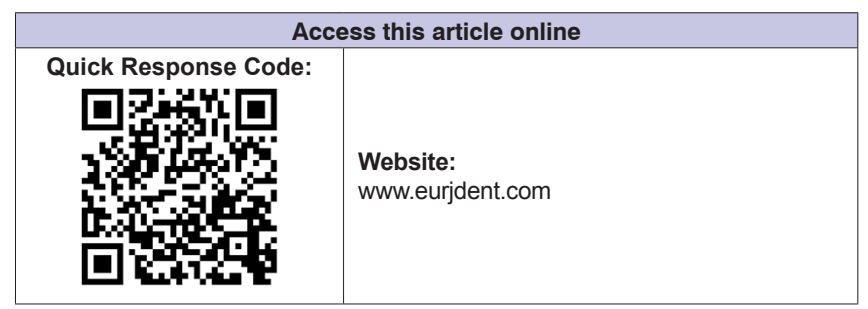

restorations are being introduced. However, there are no long-term studies or results regarding these new materials; hence, their advantages and disadvantages compared to the traditional provisional

This is an open access journal, and articles are distributed under the terms of the Creative Commons Attribution-NonCommercial-ShareAlike 4.0 License, which allows others to remix, tweak, and build upon the work non-commercially, as long as appropriate credit is given and the new creations are licensed under the identical terms.

For reprints contact: reprints@medknow.com

How to cite this article: Almohareb T, Alkatheeri MS, Vohra $F$, Alrahlah A. Influence of experimental staining on the color stability of indirect computer-aided design/computer-aided manufacturing dental provisional materials. Eur J Dent 2018;12:269-74.

DOI: 10.4103/ejd.ejd_1_18 
restorations need to be reviewed. Due to the major mainstream demand of highly esthetic restorations, provisional restorations are essential and could be used as an early reflection of the final restoration. However, it is necessary to determine the optimal esthetic material for use in durable provisional restorations, for instance, in full-mouth prosthetic rehabilitations expected to function for extended time periods. ${ }^{[1-4]}$ The existing materials for constructing provisional restorations contain autopolymerizing polymethyl methacrylate (PMMA), polyethylene methacrylate, polyvinyl methacrylate, urethane methacrylate, bis-acryl, and microfilled resin, which can be photopolymerized, chemical polymerized, or dual cured. ${ }^{[5,6]}$ PMMA-based resins are less prone to discoloration as compared to other provisional resins, including bis-acryls. However, some studies have reported similar color stability for bis-acryl and PMMA. ${ }^{[7-11]}$

According to the CIELAB system recommended by the American Dental Association, all natural colors can be derived from a combination of three basic colors: red, blue, and green. ${ }^{[12-14]}$ Photometric and colorimetric instruments can be used to determine color, showing it in terms of three-coordinate system $\left(L^{*}, a^{*}\right.$, and $\left.b^{*}\right)$, which indicates a sample's color inside the CIELAB color space. Brightness is indicated by $L^{*}$ coordinate in color space coordinates, $a^{*}$ value indicates the red or green chroma, and the value of $b^{*}$ indicates the yellow or blue chroma. The variation in the values of these coordinates can be used to determine the color variation $(\Delta \mathrm{E})$ of two objects. There are various thresholds of color difference values above which the color difference is perceptible and in other cases acceptable to the human eye. However, a benchmark $(\Delta \mathrm{E})$ value of 4.2 or less is supposed to be visually invisible as well as clinically acceptable. ${ }^{[14-19]}$

Computer-aided design/computer-aided manufacturing (CAD/CAM) provisional indirect restorations offer the advantages of improved accuracy of fit, superior contour, and exacting occlusion. A critical factor in the success of esthetic zone provisional crowns and fixed partial dentures is their color stability and resistance to stain. It is hypothesized that the color stability of novel $\mathrm{CAD} / \mathrm{CAM}$ provisional restorations is comparable to conventionally fabricated provisionals. To our knowledge, studies assessing the color stability of novel CAD/CAM-fabricated materials to conventional materials are limited. The objective of this in vitro study is to conduct a comparative analysis of the color stability of CAD/CAM-fabricated provisional restorations with those of conventionally fabricated provisional restorations.

\section{MATERIALS AND METHODS}

Four solutions such as Pepsi (Riyadh, Saudi Arabia), coffee, tea, and distilled water were used to test the color stability of three provisional restorative materials (PMMA [Systemp C\&B], bis-acryl[Protemp4], and PMMA [Telio CAD]) [Table 1]. All the provisional materials used had A1 shade. Initially, a wax block of $2 \mathrm{~mm} \times 5 \mathrm{~mm} \times 5 \mathrm{~mm}$ was made, and silicon putty mold was fabricated around it. Forty rectangular samples were made for each material using a silicon mold with injection molding. For materials, Systemp C\&B or Protemp 4 was injected into the mold and the excess was removed from the top. Both materials were allowed to self-cure for 5 min followed by light curing (Bluephase ${ }^{\circledR}$, Ivoclar Vivadent, Schaan, Liechtenstein) at a light intensity of $1000 \mathrm{~mW} / \mathrm{cm}^{2}$ for $10 \mathrm{~s}$ for each surface. For CAD/CAM specimens, each specimen was fabricated according to the manufacturer's instructions. The block was scanned by means of CEREC inEos system (Sirona, Bensheim, Germany). To achieve a thin and smooth surface of the powder, the scan spray (Vita Zahnfabrik, Germany) was applied to the block by means of a propellant. CEREC 3D v3.60 software was used for the designing of CAD/CAM specimens. The CAD/CAM specimens were milled using default milling burs (1.2 mm cylinder bur, step bur). After the milling, the specimens were inspected for the existence of any flaws or cracks. After fabrication, all specimens were finished with silicon carbide

\begin{tabular}{lll}
\multicolumn{2}{l}{ Table 1: Materials used } & \\
\hline Material & Composition & Manufacturer \\
\hline Systemp C\&B II & $\begin{array}{l}\text { Polyfunctional methacrylates (48 wt\%) } \\
\text { inorganic filler (47 wt\%), plasticizers, catalysts, } \\
\text { stabilizers and pigments (5 wt\%) }\end{array}$ & Ivoclar Vivadent, Schaan, Liechtenstein \\
Telio CAD & PMMA & Ivoclar Vivadent, Schaan, Liechtenstein \\
Protemp 4 & Dimethacrylate polymer, bisGMA, Zirconia Silica, Fumed \\
& Silica, Silane Pigments & 3M ESPE, Neuss, Germany \\
\hline \multicolumn{2}{l}{ PMMA: Polymethyl methacrylate, CAD: Computer-aided design } \\
\hline
\end{tabular}


grinding papers (No. 120, 200, and 800), polished with diamond polishing paste, and this was followed by washing with distilled water. The three provisional materials were divided into four subgroups each, resulting in a total of 12 groups $(n=10)$. The color of all the specimens was studied with Color-Eye ${ }^{\circledR}$ 7000A spectrophotometer [Figure 1] using CIELAB before (control) and after solution immersion.

Tea was prepared by immersing two tea bags into $300 \mathrm{ml}$ of boiling water for $5 \mathrm{~min}$. Five grams of coffee was mixed in $300 \mathrm{ml}$ of boiling water and filtered after $1 \mathrm{~min}$. Pepsi and distilled water were used as pure solutions. All solutions were refreshed every day. Specimens were immersed in standard concentrations of tea, coffee, Pepsi, and distilled water for 28 days [Table 2]. The solutions were refreshed every 2 days. After 7 days of immersing, specimens were rinsed with water, brushed with a soft tooth brush (GlaxoSmithKline, United Kingdom), and dried with absorbent paper towels after which the second color assessment was performed. Before each test run, the instrument was calibrated as per the manufacturer's instructions. Triplet readings were taken for each sample, and the mean values of $L^{*}, a^{*}$, and $b^{*}$ were recorded. After baseline readings were taken, specimens were stored in the solutions for 1 week at $37^{\circ} \mathrm{C}$. The solutions were changed every 3 days and stirred once a day manually. Before the second measurements, all the specimens were washed using distilled water and paper dried. This sequence of activities was repeated every week for 4 weeks. The color difference $(\Delta \mathrm{E})$ was calculated using the given equation:

$$
\Delta E=\left[\left(\Delta L^{*}\right)^{2}+\left(\Delta a^{*}\right)^{2}+\left(\Delta b^{*}\right)^{2}\right]^{1 / 2}
$$

The obtained data were statistically analyzed using three-way analysis of variance (ANOVA) $(\alpha=0.05)$. Study groups were compared using one-way ANOVA and Tukey's post hoc tests (at $\alpha=0.05$ ) using a statistical software (SPSS v10; SPSS Inc., Chicago, IL, USA).

\section{RESULTS}

Assessment for color change $(\Delta \mathrm{E})$ was done every week for 4 weeks (28 days). The maximum color change when specimens were soaked in distilled water and coffee was observed at 4 weeks in Protemp [Tables 3 and 4]. The maximum color change when samples were immersed in Pepsi and tea was observed for Systemp C\&B at

\begin{tabular}{lll}
\multicolumn{2}{l}{ Table 2: Composition of solutions } & \\
\hline Solutions & Composition & Manufacturer \\
\hline 1. Pepsi & $\begin{array}{l}\text { Carbonated water, high-fructose } \\
\text { corn syrup, caramel color, sugar, } \\
\text { phosphoric acid, caffeine, citric }\end{array}$ & PepsiCo \\
& $\begin{array}{l}\text { acid, and natural flavors } \\
\text { Lipton Yellow Label Tea }\end{array}$ & Lipton \\
$\begin{array}{l}\text { 2. Tea } \\
\text { 3. Coffee }\end{array}$ & Nescafe Classic Instant Coffee & Nescafe \\
4. Distilled & $\mathrm{H}_{2} \mathrm{O}$ & \\
water & & \\
\hline
\end{tabular}

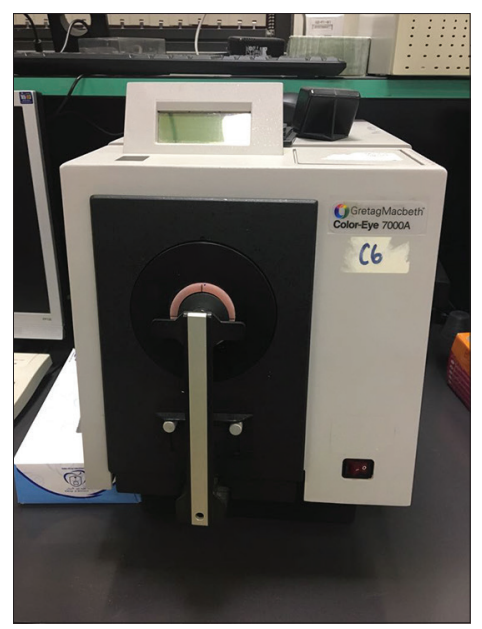

Figure 1: Spectrophotometer

4 weeks [Tables 5, 6 and Figure 2]. Telio CAD (CAD/ CAM) provisional material at 4 weeks showed the least color change among all the study groups when immersed in different solutions [Figure 3]. At 1-week interval, for Pepsi and water immersion solutions, least color change was observed for Protemp provisional material. However, Telio CAD showed minimum color change at 1-week interval in coffee and tea [Tables 3-6 and Figures 2 and 3].

Irrespective of the immersion solutions, Systemp C\&B showed highest color change $(3.068 \pm 0.15)$ and CAD/CAM provisional material showed least color change $(2.312 \pm 0.15)$ [Figures 3 and 4 ]. Color change was significantly lower in CAD/CAM material; however, color change was comparable among samples of Systemp C\&B and Protemp $(P=0.29)$. For immersion solutions, the highest-to-lowest color change was observed due to coffee, tea, Pepsi, and distilled water. There was significant difference in color stability of samples based on staining immersion solutions $(P<0.01)$. The influence of duration of immersion had a significant effect on the color stability of provisional crown and bridge materials $(P<0.01)$. The mean change in color $(\Delta \mathrm{E})$ was shown at 1-week immersion $(2.248 \pm 0.042)$ and the maximum was 


\begin{tabular}{|c|c|c|c|c|}
\hline Distill water & 1 & 2 & 3 & 4 \\
\hline Systemp C\&B II & $2.02(0.28)^{\mathrm{a}, \mathrm{A}}$ & $2.01(0.28)^{\mathrm{a}, \mathrm{A}}$ & $2.31(0.16)^{\mathrm{a}, \mathrm{A}}$ & $2.40(0.14)^{\mathrm{a}, \mathrm{a}}$ \\
\hline Telio CAD & $1.61(0.28)^{a, b, A}$ & $1.62(0.27)^{\mathrm{b}, \mathrm{A}}$ & $1.67(0.24)^{\mathrm{b}, \mathrm{A}}$ & $1.85(0.26)^{\mathrm{b},}$ \\
\hline Protemp 4 & $0.96(0.90)^{\mathrm{b}, \mathrm{A}}$ & $1.03(0.10)^{c, A}$ & $1.13(0.10)^{\mathrm{c}, \mathrm{A}}$ & $2.75(0.14)^{\mathrm{c}, \mathrm{B}}$ \\
\hline
\end{tabular}

\begin{tabular}{lcccc}
\multicolumn{4}{l}{ Table 4: Mean $\boldsymbol{\Delta E}$ (standard deviation) at different time intervals when immersed in coffee } \\
\hline Coffee & $\mathbf{1}$ & $\mathbf{2}$ & $\mathbf{3}$ & $\mathbf{4}$ \\
\hline Systemp C\&B II & $2.66(0.54)^{\mathrm{a}, \mathrm{A}}$ & $4.24(0.35)^{\mathrm{a}, \mathrm{B}}$ & $4.88(0.43)^{\mathrm{a}, \mathrm{B}, \mathrm{C}}$ & $5.27(0.44)^{\mathrm{a}, \mathrm{C}}$ \\
Telio CAD & $2.02(0.21)^{\mathrm{a}, \mathrm{A}}$ & $2.72(0.34)^{\mathrm{b}, \mathrm{B}}$ & $2.89(0.34)^{\mathrm{b}, \mathrm{B}}$ & $4.69(0.47)^{\mathrm{a}, \mathrm{C}}$ \\
Protemp 4 & $4.80(0.37)^{\mathrm{b}, \mathrm{A}}$ & $5.77(0.46)^{\mathrm{c}, \mathrm{B}}$ & $6.22(0.13)^{\mathrm{c}, \mathrm{B}}$ & \\
\hline
\end{tabular}

The same superscript small letters indicate no significant differences (columns) $(P>0.05)$, and the same superscript capital letters indicate no significant differences (rows) $(P>0.05)$. CAD: Computer-aided design

\begin{tabular}{|c|c|c|c|c|}
\hline Tea & 1 & 2 & 3 & 4 \\
\hline Systemp C\&B II & $2.73(0.62)^{a, b, A}$ & $3.45(0.54)^{a, A, B}$ & $4.14(0.42)^{\mathrm{a}, \mathrm{B}}$ & $5.10(0.42)^{\mathrm{a}, \mathrm{c}}$ \\
\hline Telio CAD & $2.09(0.23)^{\mathrm{a}, \mathrm{A}}$ & $2.64(0.20)^{\mathrm{b}, \mathrm{B}}$ & $3.06(0.16)^{\mathrm{b}, \mathrm{B}}$ & $3.94(0.36)^{b, C}$ \\
\hline Protemp & $3.29(0.36)^{\mathrm{b}, \mathrm{A}}$ & $3.31(0.34)^{\mathrm{a}, \mathrm{A}}$ & $3.82(0.46)^{a, A, B}$ & $4.34(0.44)^{b, B}$ \\
\hline
\end{tabular}

\begin{tabular}{lcccc} 
Table 6: Mean $\Delta E$ (standard deviation) at $\mathbf{4}$ weeks & when immersed in Pepsi \\
\hline Pepsi & $\mathbf{1}$ & $\mathbf{2}$ & $\mathbf{3}$ & $\mathbf{4}$ \\
\hline Systemp C\&B & $1.95(0.17)^{\mathrm{a}, \mathrm{A}}$ & $2.87(0.16)^{\mathrm{a}, \mathrm{B}}$ & $3.46(0.50)^{\mathrm{a}, \mathrm{B}}$ & \\
Telio CAD & $1.82(0.20)^{\mathrm{a}, \mathrm{A}}$ & $2.07(0.11)^{\mathrm{b}, \mathrm{A}}$ & $2.31(0.22)^{\mathrm{b}, \mathrm{B}}$ & $4.81(0.45)^{\mathrm{a}, \mathrm{C}}$ \\
Protemp & $1.04(0.65)^{\mathrm{b}, \mathrm{A}}$ & $1.18(0.10)^{\mathrm{c}, \mathrm{A}}$ & $3.45(0.13)^{\mathrm{a}, \mathrm{B}}$ & $2.92(0.26)^{\mathrm{b}, \mathrm{B}}$ \\
\hline The same superscript small letters indicate no significant differences (columns) $(P>0.05)$, and the same superscript & $3.70(0.16)^{\mathrm{c}, \mathrm{B}}$ \\
\hline
\end{tabular}

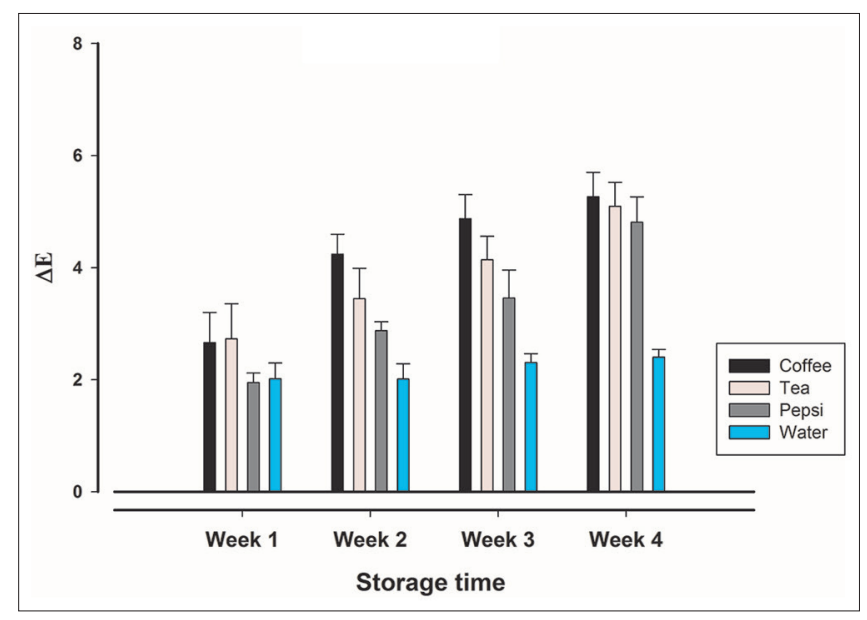

Figure 2: Mean color change values $(\Delta \mathrm{E})$ of SystempC\&B during 4 weeks

observed at 4 weeks $(4.066 \pm 0.043)$ with a linear relationship.

Data analysis revealed that the highest color stability was found in CAD/CAM material, followed by Protemp and Systemp C\&B. It was also observed that the maximum color variation was recorded in case of coffee followed by tea and Pepsi.

\section{DISCUSSION}

This study compared the color stability of CAD/ CAM-fabricated provisional materials with those of conventional, manually fabricated provisional materials. It was hypothesized that the color stability of novel CAD/CAM provisional restorations is comparable to conventionally fabricated provisionals. In the present study, color stability was significantly higher for CAD/CAM provisional material as compared to other conventional provisional materials (Systemp C\&B and Protemp); therefore, the hypothesis was rejected. PMMA-based CAD/CAM blocks are prepolymerized under optimized parameters, allowing for maximum monomer-to-polymer conversion. This intern improves the overall mechanical properties of the provisional restorative material as compared to conventional, manually fabricated materials. Therefore, CAD/CAM provisionals can be of clinical use in cases 


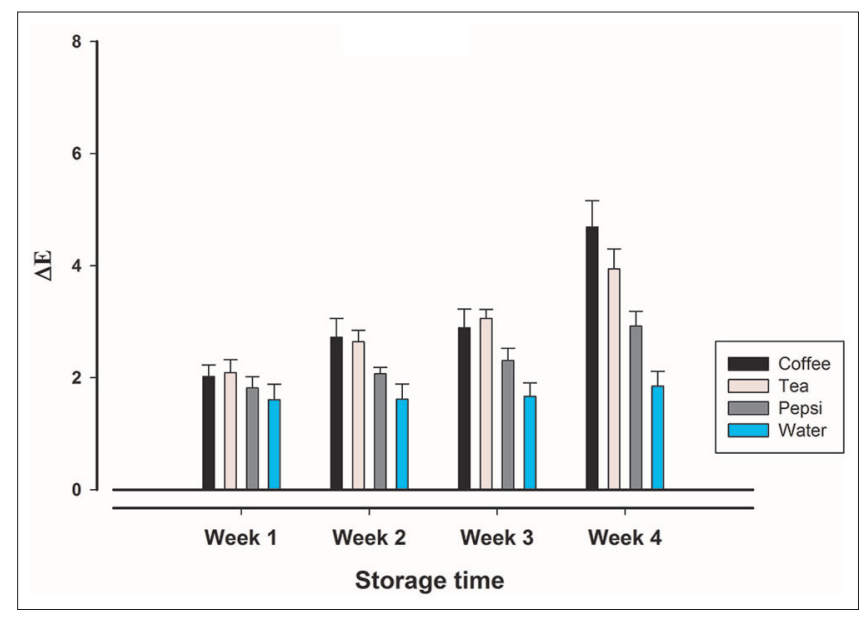

Figure 3: Mean color change values $(\Delta \mathrm{E})$ of Telio CAD during 4 weeks

where long-term provisional is required due to better strength and color stability. ${ }^{[20-22]}$ As tooth-colored dental restorations frequently come in contact with saliva, soft drinks, and food stains, it is essential to evaluate their color stability. Intrinsic color stability as well as staining resistance for an extended period of time are required to confirm restorations imperceptibility. Although long-term tests are required for clinical studies to attain results, yet, numerous short-term laboratory scale tests have been conducted in a short time to assess the discoloration, simulating oral aging environment. ${ }^{[23]}$ In this in vitro study, the color of CAD/CAM and conventional provisional materials was recorded after various immersion times, at baseline and weekly up to 4 weeks. The CIELAB system for evaluating chromacity was selected to measure color variations due to its suitability for minor color variations. Measurements taken by the use of spectrophotometers and colorimeters have been used to assess color variation in various dental restoration specimens. ${ }^{[8]}$ When evaluating reflective surfaces, the obtained color is affected by both the actual colors of the specimen's surface and the measuring parameters. In the current study, a typical illuminant against a white background was used. In addition, as it is established from the previous reports that the smoothness and thickness of the specimen surface affect color stability of materials, ${ }^{[24]}$ in this study, the thickness of provisional restorative material was standardized to $2 \mathrm{~mm}$.

Various thresholds of color difference values $(\Delta \mathrm{E} 1-3.7)$ are reported previously, which are considered perceptible to the naked eye. ${ }^{[25]}$ In the present study, specimens showed $\Delta \mathrm{E}$ values with water immersion to be under the perceptible changes, i.e. $\Delta \mathrm{E}$ value of 2.7, indicating acceptable color stability for the tested provisional materials in controlled

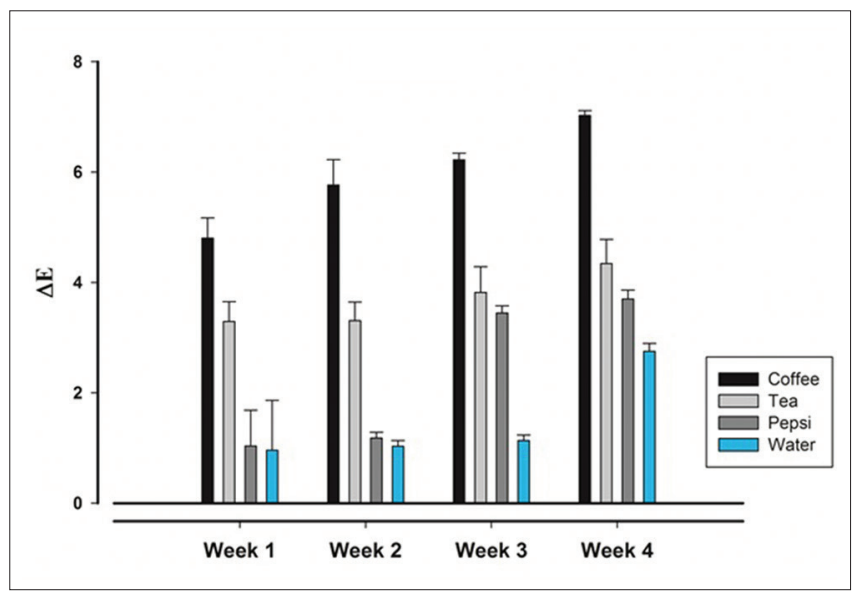

Figure 4: Mean color change values $(\Delta \mathrm{E})$ of ProtempC\&B during 4 weeks

conditions. However, with the exception of CAD/ CAM provisionals, at 3 - and 4-week staining solution immersion, conventional provisional materials showed significant changes in color with $\Delta \mathrm{E}$ values of 3.4-6.2 at 3 weeks and 3.7-7 at 4 weeks. Both SystempC\&B and Protemp showed clinically unacceptable color changes; however, these findings have been described previously by other researchers. ${ }^{[10,26]}$ In the present study, Protemp showed highest color changes compared to other specimens. Protemp is a bis-acryl-based material and higher uptake of stains from immersion solutions with greater color changes have been reported for it in previous studies. ${ }^{[10,27]}$ Color stability in PMMA provisional materials is influenced by multiple factors, including pigment stability, initiator system, monomer-to-polymer conversion ratio, water sorption, and distribution of monomer particles. ${ }^{[26]}$ Conventional PMMA provisionals in the present study (Systemp C\&B) showed significantly higher color change as compared to PMMA-based CAD/CAM provisionals. This could be attributed to the optimal condition during which polymerization of CAD/CAM materials takes place, therefore resulting in improved monomer-to-polymer conversion rate in addition to low polymerization shrinkages. ${ }^{[28]}$ In addition, preparation errors are more pronounced in conventionally fabricated PMMA provisionals as compared to CAD/CAM provisionals, hence resulting in a compromised color stability. Interestingly, the highest color change was shown by coffee, followed by tea and Pepsi in the present study. Ergün et al. ${ }^{[29]}$ in a similar previous study had shown strong discoloration of provisional materials due to coffee; this was attributed to the smaller molecular size along with water absorption characteristic of the tested materials. 
Therefore, in light of the observations in the present study, the authors recommend the clinical use of CAD/CAM provisionals for improved esthetic success due to enhanced color stability.

\section{CONCLUSIONS}

Within the limitations of this study, CAD/CAM provisional material (Telio CAD) showed better color stability compared to Protemp 3M ESPE and Systemp C\&B Ivoclar Vivadent and is recommended for long-term provisional restorations. This is attributed to the prepolymerization, higher monomer conversion, and minimal preparation errors in CAD/ CAM materials.

\section{Acknowledgment}

The authors would like to express their gratitude to the intern group (Dr. Abdulaziz Algaith, Dr. Abdulaziz Almalaq, and Dr. Abdulelah Almusalm) for their valuable assistance in sample preparation. In addition, the authors would like to thank the College of Dentistry Research Center and Deanship of Scientific Research at King Saud University, Saudi Arabia, for supporting this research project (Research Project Number IR 0214).

\section{Financial support and sponsorship}

Nil.

\section{Conflicts of interest}

There are no conflicts of interest.

\section{REFERENCES}

1. Tahayeri A, Morgan M, Fugolin AP, Bompolaki D, Athirasala A, Pfeifer CS, et al. 3D printed versus conventionally cured provisional crown and bridge dental materials. Dent Mater 2018;34:192-200.

2. Patras M, Naka O, Doukoudakis S, Pissiotis A. Management of provisional restorations' deficiencies: A literature review. J Esthet Restor Dent 2012;24:26-38.

3. Perry RD, Magnuson B. Provisional materials: Key components of interim fixed restorations. Compend Contin Educ Dent 2012;33:59-60, 62.

4. Kurtzman GM, Strassler HE, Fadm F. Provisional fixed restorations. Dent Econ 2006;3:1-12.

5. Astudillo-Rubio D, Delgado-Gaete A, Bellot-Arcís C, Montiel-Company JM, Pascual-Moscardó A, Almerich-Silla JM, et al. Mechanical properties of provisional dental materials: A systematic review and meta-analysis. PLoS One 2018;13:e0193162.

6. Christensen GJ. The fastest and best provisional restorations. J Am Dent Assoc 2003;134:637-9.

7. Doray PG, Li D, Powers JM. Color stability of provisional restorative materials after accelerated aging. J Prosthodont 2001;10:212-6.

8. Ardu S, Duc O, Di Bella E, Krejci I. Color stability of recent composite resins. Odontology 2017;105:29-35.

9. Yu YT. Evaluation of color stability of temporary restorative materials exposed to different cleaning solutions. Boston Univ Doct Diss 2017.

10. Sham AS, Chu FC, Chai J, Chow TW. Color stability of provisional prosthodontic materials. J Prosthet Dent 2004;91:447-52.

11. Doray PG, Wang X, Powers JM, Burgess JO. Accelerated aging affects color stability of provisional restorative materials. J Prosthodont 1997;6:183-8.

12. Seghi RR, Gritz MD, Kim J. Colorimetric changes in composites resulting from visible-light-initiated polymerization. Dent Mater 1990;6:133-7.

13. Canay S, Hersek N, Tulunoğlu I, Uzun G. Evaluation of colour and hardness changes of soft lining materials in food colorant solutions. J Oral Rehabil 1999;26:821-9.

14. Okubo SR, Kanawati A, Richards MW, Childress S. Evaluation of visual and instrument shade matching. J Prosthet Dent 1998;80:642-8.

15. Alghazali N, Burnside G, Moallem M, Smith P, Preston A, Jarad FD, et al. Assessment of perceptibility and acceptability of color difference of denture teeth. J Dent 2012;40 Suppl 1:e10-7.

16. Villalta P, Lu H, Okte Z, Garcia-Godoy F, Powers JM. Effects of staining and bleaching on color change of dental composite resins. J Prosthet Dent 2006;95:137-42.

17. Sarkis E. Color change of some aesthetic dental materials: Effect of immersion solutions and finishing of their surfaces. Saudi Dent J 2012;24:85-9.

18. Ruyter IE, Nilner K, Moller B. Color stability of dental composite resin materials for crown and bridge veneers. Dent Mater 1987;3:246-51.

19. Seghi RR, Hewlett ER, Kim J. Visual and instrumental colorimetric assessments of small color differences on translucent dental porcelain. J Dent Res 1989;68:1760-4.

20. Lodding DW. Long-term esthetic provisional restorations in dentistry. Curr Opin Cosmet Dent 1997;4:16-21.

21. Burke FJ, Sands P. Use of a novel resin composite crown as a long-term provisional. Dent Update 2009;36:481-4, 486-7.

22. Proussaefs P. Immediate provisionalization with a CAD/CAM interim abutment and crown: A guided soft tissue healing technique. J Prosthet Dent 2015;113:91-5.

23. Janda R, Roulet JF, Kaminsky M, Steffin G, Latta M. Color stability of resin matrix restorative materials as a function of the method of light activation. Eur J Oral Sci 2004;112:280-5.

24. Koishi Y, Tanoue N, Matsumura H, Atsuta M. Colour reproducibility of a photo-activated prosthetic composite with different thicknesses. J Oral Rehabil 2001;28:799-804.

25. Ceci M, Viola M, Rattalino D, Beltrami R, Colombo M, Poggio C, et al. Discoloration of different esthetic restorative materials: A spectrophotometric evaluation. Eur J Dent 2017;11:149-56.

26. Haselton DR, Diaz-Arnold AM, Dawson DV. Color stability of provisional crown and fixed partial denture resins. J Prosthet Dent 2005;93:70-5.

27. Givens EJ Jr., Neiva G, Yaman P, Dennison JB. Marginal adaptation and color stability of four provisional materials. J Prosthodont 2008;17:97-101.

28. Elagra MI, Rayyan MR, Alhomaidhi MM, Alanaziy AA, Alnefaie MO. Color stability and marginal integrity of interim crowns: An in vitro study. Eur J Dent 2017;11:330-4.

29. Ergün G, Mutlu-Sagesen L, Ozkan Y, Demirel E. In vitro color stability of provisional crown and bridge restoration materials. Dent Mater J 2005;24:342-50. 